\title{
Mycorrhizal Association: An Important Tool for the Management of Root Diseases
}

\author{
Mashoq Ahmad ${ }^{1}$, Baby Summuna ${ }^{1 *}$, Sachin Gupta ${ }^{2}$ and P.A. Sheikh ${ }^{1}$ \\ ${ }^{1}$ SKUAST- Kashmir, India \\ ${ }^{2}$ SKUAST- Jammu, India \\ *Corresponding author
}

\section{A B S T R A C T}

Keywords

Mycorrhiza, Symbiotic association, $\mathrm{AMF}$

\section{Article Info}

Accepted:

15 August 2020

Available Online:

10 September 2020
Mycorrhizae is a symbiotic mutualistic relationship between special soil fungi and fine plant roots. Interaction of Mycorrhiza with plants, fungi and environment is obligatory and somewhat complex. Mycorrhiza fungi offer substantial benefits to associated plants like increase in mineral nutrient uptake, protection against soil borne pathogens, damage compensation etc (Ranganathswamy et al., 2019). Improvement of plant nutrition, compensation for pathogen damage, and competition for photosynthates or colonization/infection sites have been claimed to play a protective role by mycorrhizae (Aguilar and Barea, 1997). AMF colonization significantly increased shoot weight, root weight, and root surface area by $30 \%, 35 \%$, and $22 \%$, respectively, compared to the non-AMF treatment. Compared with non-AMF seedlings also mycorrhizal seedlings recorded notably higher root $\mathrm{P}, \mathrm{Ca}, \mathrm{Mg}$, and $\mathrm{Fe}$ concentrations of $75 \%, 10 \%, 19 \%, 18 \%$, respectively as compared to non- AMF seedlings (Lu et al., 2019).Glomus spp. individually or in combination with $B$. subtilis or $T$. viride significantly reduced root-rot disease of sesame and significantly increased shoot length, fresh weight of shoot system and number of pods per plant (Ziedan et al., 2011).

\section{Introduction}

The word mycorrhiza is derived from classical Greek word for "mushroom" and "root". In a mycorrhizal association, the underground mycellium are in contact with plant roots, but without causing any harm to the plant. Fossil evidence (Remy et al., 1994) and DNA sequence analysis (Simon et al.,
1993) suggest that this mutualism appeared 400-460 million years ago. Vesicular arbuscular mycorrhizal fungi belong to the class Zygomycetes, order Endogonales (Benjamin, 1979) and family Endogonaceae. Mycorrhizal fungi are responsible in improving growth of host plant species due to increased nutrient uptake, production of growth promoting substances, tolerance to 
drought, salinity and synergistic interactions with other beneficial microorganisms (Sreenivasa and Bagyaraj, 1989). The soil conditions prevalent in sustainable agriculture are likely to be more favorable to AM fungi than are those under conventional agriculture (Bethlenfalvay and Schuepp, 1994; Smith and Read, 1997). The AM fungi are widely distributed in natural and agricultural environments and have been found associated with more than $80 \%$ of land plants, liverworts, ferns, woody gymnosperms and angiosperms and grasses (Smith and Read, 2008).

The natural role of mycorrhizosphere organisms may have been marginalized in intensive agriculture, since microbial communities in conventional farming systems have been modified due to tillage and high inputs of inorganic fertilizers, herbicides and pesticides. Microbial diversity in these systems has been reduced and the functional consequences of this loss of diversity are still uninvestigated. Indiscriminate use of inorganic fertilizers contributes enormously in stepping up agricultural production regionally and globally but at the same time its impact on soil fertility, environmental persistence, soil biodiversity, run off concentration and aquaculture pollution cannot be viewed superficially.

Increased environmental awareness has progressively led to shift from conventional intensive management to low input crop production. Conceivably, a wide range of management are available for the management of disease constraints in various crops, but their effective implementation depends on a sound understanding of the physiological response of plants to these stresses. The present article aims to review the main mechanisms involved in the biological control of diseases induced by soil borne phytopathogens after root colonization with AM fungi.

\section{Distribution of mycorrhizal fungi}

Mycorrhizal association is present in $83 \%$ Dicots, $79 \%$ Monocots, $100 \%$ Gymnosperms. This association is not present in families of Amaranthaceae,

Brasicaceae, Caryophyllaceae, Chenopodiaceae, Commelinaceae, Lecythidaceae, Portulaceae, Proteaceae, Restionaceae, Sapotaceae, Zygophyllaceae.

\section{Types of association}

Mycorrhizas were traditionally classified into the two types: ectotrophic and endotrophic, a classification based on the location of the fungal hyphae in relation to the root tissues of the plant; ecto means outside the root, endo means inside.

Endomycorrhizas; in which the fungal structure is almost entirely within the host root, comprising three major and two minor groupings:

Arbuscular (AM) endomycorrhizas, are the commonest mycorrhizas, and were the first to evolve; the fungi are members of the Glomeromycotina, they are obligate biotrophs, and they are associated with roots of about $80 \%$ of plant species, including many crop plants. The AM association is endotrophic, and has previously been referred to as Vesicular-Arbuscular Mycorrhiza (VAM).

Ericoid endomycorrhizas are mycorrhizas of Erica (heather), Calluna (ling) and Vaccinium (bilberry), that is, plants that endure moorlands and similar challenging environments. Fungi are members of the Ascomycota (an example is Hymenos cyphusericae. The plant's rootlets are covered with a sparse network of hyphae; the fungus digests polypeptides saprotrophically and passes absorbed nitrogen to the plant host; in 
extremely harsh conditions the mycorrhiza may even provide the host with carbon sources (by metabolising polysaccharides and proteins for their carbon content).

\section{Arbutoidendo \\ mycorrhizas Monotropoidendo mycorrhizas (the mycorrhizal association formed by the achlorophyllous plants of the Montropaceae).}

Orchidaceous endomycorrhizas are similar to ericoid mycorrhizas but their carbon nutrition is even more dedicated to supporting the host plant, as the young orchid seedling is non-photosynthetic and depends on the fungus partner utilising complex carbon sources in the soil, and making carbohydrates available to the young orchid. All orchids are achlorophyllousin the early seedling stages, but usually chlorophyllous as adults, so in this case the seedling stage orchid can be interpreted as parasitising the fungus. A characteristic fungus example is the basidiomycete genus Rhizoctonia (although this is a complex genus which can be divided into several new genera).

Ectomycorrhizas are the most advanced symbiotic association between higher plants and fungi, involving about $3 \%$ of seed plants including the majority of forest trees. In this association the plant root system is completely surrounded by a sheath of fungal tissue which can be more than $100 \mu \mathrm{m}$ thick, though it is usually up to $50 \mu \mathrm{m}$ thick. The hyphae penetrate between the outermost cell layers forming what is called the Hartig net. From this a network of hyphal elements (hyphae, strands and rhizomorphs) extend out to explore the soil domain and interface with the fungal tissue of the root. Ectomycorrhizal fungi are mainly Basidiomycota and include common woodland mushrooms, such as Amanita spp., Boletus spp., Tricholoma spp. Ectomycorrhizas can be highly specific (for example Boletus elegans with larch) and non- specific (for example Amanita muscaria with 20 or more tree species. In the other specificity direction, forty fungal species are capable of forming mycorrhizas with pine.

Ectomycorrhizas can link together groups of trees (the submerged mycelium acting as what has been described as a 'wood wide web' or, more formally, 'Common Mycorrhizal Networks' (Gilbert \& Johnson, 2017). Ectomycorrhizal fungi depend on the plant host for carbon sources, most being uncompetitive as saprotrophs. With few exceptions (Tricholoma fumosum being one), the fungi are unable to utilise cellulose and lignin; but the fungus provides greatly enhanced mineral ion uptake for the plant and the fungus is able to capture nutrients, particularly phosphate and ammonium ions, which the root cannot access. Host plants grow poorly when they lack ectomycorrhizas. This ectomycorrhizal group is reasonably homogenous, but a subgroup, ectendomycorrhizas, has been appended.

Ectendomycorrhiza is a purely descriptive name for mycorrhizal roots that exhibit characteristics of both ectomycorrhizas and endomycorrhizas. Ectendomycorrhizas are essentially restricted to the plant genera Pinus (pine), Picea (spruce) and, to a lesser extent, Larix (Larch). Ectendomycorrhizas have the same characteristics as endomycorrhizas but also show extensive intracellular penetration of the fungal hyphae into living cells of the host root.

\section{Mechanism of Root disease suppression}

Soil borne pathogens were controlled by using several agricultural practices methods, such as resistant cultivars, seed certification, chemical fungicides, crop rotation and soil fumigation etc. There are many problems associated with controlling pathogens with long-term persistent survival structures due to 
difficulties in reducing pathogen inoculum and lack of good sources of plant resistance (Azcon-Aguliar and Barea, 1997). Therefore, many researchers were trying to use alternate approaches based on either manipulating or adding microorganisms to enhance plant protection against pathogens (Grosch et al., 2005). The beneficial microorganisms (antagonistic bacteria) (e.g., Pseudomonas fluorescens, Bacillus subtilis, etc.) and fungi (e.g., AMF, Trichoderma, etc.) compete with plant pathogens for nutrients and space, by producing antibiotics, by parasitizing pathogens, or by inducing resistance in the host plants.

Enhancing plant nutrition uptake: Improvements in plant growth followed by root colonization by AMF occurs as a result of enhancement of the mineral nutrient status of plants. Some reports indicate that phosphorus induced changes in root exudation could reduce the germinations of pathogen spores (Graham, 1982; Sharma et al., 2007). Some studies suggest that competition for space between AMF and pathogen, AMF may increase host tolerance to pathogen by increasing the uptake of essential nutrients rather than phosphorus which are otherwise deficient in the non-mycorrizal plants (Gosling et al., 2006). The AMF spores germinate and thick-walled hyphae penetrate the host root causing internal infection. After penetrating into the root, the hyphae spread inter- and/or intra-cellularly in the root cortex without damaging the integrity of the cells (Strack et al., 2003). The increasing nutrient uptake resulted in more vigorous plants; thus, the plant itself may be more resistant or tolerant to pathogen attack (Linderman, 1994)

Damage compensation: It is suggested that AMF increase host tolerance of pathogen attack by compensating for the loss of root functional and biomass caused by soilborne pathogens (Linderman, 1994) including fungi and nematodes (Cordier et al., 1996). This illustrates an indirect contribution to the biological control through the conservation of root system function both by AMF hyphae growing out into the soil and increasing the root absorbing surface area as well as by the maintenance of root cell activity through arbuscules formation (Gianinazzi-Person et al., 1995).

Soil microbial population interactions: The role of AMF in improving plant nutrition and their interactions with other soil biota have been investigated with reference to the host plant growth. Few information's known about how these interactions affect soil structure (Schreiner and Bethlenfalvay, 1995). Plants colonized by AMF differ from nonmycorrhizal plant in rhizosphere microbial community, resulted in alterations in root respiration rate quality and quantity of the exudates (Marschner et al., 2001).

The growth and health of plants influenced by the microbial shifts occur in the mycorrhizosphere. This effect has not been specifically evaluated as mechanisms for AMassociated biocontrol, but there are indications that such a mechanism does operate (Linderman, 1994). Some reports suggest that AMF alter the composition of functional groups of microbes in the mycorrhizosphere, including the numbers and/or activity of pathogens antagonists (Secilia and Bagyaraj, 1987).

\section{Competition for colonization and infection} sites: Physical competition between endomycorrhizal fungi and rhizosphere microorganisms to occupy more space in the root architecture is the first mechanism to explain the interaction between AMF and soil microorganisms. Mycorrhizal fungi depend on the plant host photosynthates, so the competition for carbon compounds maybe, a cause of the pathogen suppression in 
mycorrhizal plant. The interaction between AMF and Phytophthora in tomato plant has shown that the pathogen dose not penetrate arbuscular containing cells (Cordier et al., 1998). Dehne (1982) documented how AM fungi and root pathogens colonize in the same host tissues and how they develop in different root cortical cells, indicating some sort of or competition for space. The interaction of Glomusmosseae and phytophthoranicotiana var. parastica in tomato was shown to increase the AMF at the root apex site.

Morphological and anatomical changes: Root morphology system can be altered due to the colonization of root by AMF (Tahat et $a l ., 2008)$. Roots colonized by AMF are more highly branched compared to non colonized plants and also the adventitious root diameters are larger, which can provide more infection sites for a pathogen. Dugassa et al., (1996) found that the infection of tomato and cucumber by Fusariumwilt might slow down due to the morphological changes in the root cells of the endodermis of AM plants which include lignifications incensement. The raising lignifications may protect the roots from penetration by other pathogens, while elevating of phenolic metabolism within the host plant (Miranda, 1996).

The colonization of tomato root by Glomusmosseae lead to a bigger root size and more branching which increase the number of root tips, length, surface area and root volume (Tahat et al., 2008). Root damage by Gaeumannomyces graminis var. tritici was systemically reduced when barley plants showed high degree of mycorrhizal root colonization. Allowing mycorrhizal root infection exhibited no affect on Gaeumannomyces graminis var. tritici infection (Khaosaad et al., 2007).

Competition for host photosynthates: The growth of AMF and root pathogen depends on the host photosynthates and they compete for the carbon compounds received by the root (Smith and Read, 1997). When AMF have primary access to the photosynthates, the higher carbon demand may inhibit the pathogen growth (Linderman, 1994). AMF is dependent on the host plant for carbon source 4-20\% net photosynthates of host are transferred to the fungus; nevertheless, there is only a limited data to support this mechanism (Smith and Read, 2008).

Changes in chemical constituents of plant tissues (root exudates): Phytoalexins toxic components are not detected during the first stages of AM formation but can be detected in the later stages of symbiosis. Wall-bound peroxidase activity has been detected during the initial stage of AM colonization (AzconAguilar et al., 2002). Phytophthoraparasitica development decreased in Glomusmosseae and non $G$. mosseae parts of tomato mycorrhizal root systems in association with plant cell defense responses and accumulation of phenolics. Cortical cells containing $G$. mosseae are immune to the pathogen and exhibit a localized resistance response (Cordier et al., 1998). Corresponding proteins involved in plant defense responses have been studied in AMF symbioses; these include hydroxyproline-rich glycoproteins, phenolics peroxidases, chitinase, B-1-3 glucanasescallose deposition and PR-phathogenesis related proteins (Miranda, 1996).

Root exudates play an important role in AMF establishment symbiosis. Grandmaison et al., (1993) suggested that phenolic compounds bound to cell wall could be indirectly responsible for the resistance of AMF roots to pathogenic fungi since they increased the resistance of cell wall to the action of digestive enzymes.

Nutrient uptake: The primary goal of AMF inoculation is to increase and enhance the yield and production of plants. The main benefits of AMF are enhancing plant the 
acquisition of mineral nutrients and increasing the ability of host plants to withstand or reduce acquisition of toxic elements to growth (Clark, 1997). AMF provide a greater effective root surface area to explore greater volumes of soil and to overcome water and nutrient depletion zones around active root surfaces (Smith and Read, 2008).

Mycorrhizal plant roots have increased weight, length, number and layer diameters than the non-mycorrhizal one. Since, the average diameter of fungal hyphae is $3-4 \mu \mathrm{M}$, which is smaller than the root hair diameter (>10 $\mu \mathrm{M})$. Therefore, fungal hyphae penetrate soil pores and contact with soil so that roots hair would not able to contact. AM roots greatly enhance the acquisition of mineral nutrient in plant. Mycorrhizal research has shown the increased nutrient uptake; mainly Phosphorus (P), in mycorrhizal plants compared to non-mycorrhizal plants. Soil phosphorus absorption by mycorrhizal plants is complete and faster than the nonmycorrhizal plants, because the distance of diffusion for $\mathrm{HPO}_{4}{ }^{-2}$ and $\mathrm{H}_{2} \mathrm{PO}_{4}$ ion in the soil will be shorter to the hyphae than to the root (Li et al., 1991).

The improvement of $\mathrm{P}$ nutrition of plants has been the most recognized and well established beneficial effect of mycorrhizas (Cardoso et al., 2006). Phosphate is converted into polyphosphate by polyphosphate kinase in vacuoles (incorporated) and is transported between the hyphal tips and a sink at the symbiotic interface. Translocation rate is affected by rates of net efflux of $\mathrm{P}$ athyphal tips and net uptake. The abnormally high $\mathrm{P}$ loss from the arbuscules has been explained and two mechanisms have been proposed in this connection: Firstly, a high arbuscular P concentration will reduce hyphal reabsorption of lost $\mathrm{P}$ and this is in accordance with low expression of high $\mathrm{P}$ affinity transporter in the fungal tissue inside roots, compared to its expression level in the external hyphae. Secondly, P efflux may be promoted by altered operation of transmembrane that is carrying and opening of ion channels. Mycorrhizal fungi are able to mobilize $\mathrm{P}$ and $\mathrm{N}$ from their organic substrates (Smith and Read, 1997).

AMF is the most efficient ecological factor in improving growth and $\mathrm{N}$ content in legumes. Enhanced nitrogen $(\mathrm{N})$ acquisition by AM plants has been reported. This enhancement has been explained by high nitrogen demand because of enhanced phosphorus. The uptake and translocation of nitrogen by hyphal fungus is regulated by host plant's demand for N (Hawkins and George, 2001).

Enhance tolerance to heavy metals (bioremediation): The effect of AMF plants on trace elements uptake was reported (Clark and Zeto, 2000). The AMF have higher shoot concentrations of copper $(\mathrm{Cu})$ and zinc $(\mathrm{Zn})$ when grown in soil with low concentration of these elements. Copper and zinc concentrations increased in leaves of AM soybean plants compared to nonmycorrhizal plants. Sulfur acquisition was enhanced in sorghum colonized by Glomus fasciculatum compared to non colonized plants (Raju et al., 1990). Boron content was increased in AM maize shoot in acidic and alkaline soils while the acquisition of calcium $(\mathrm{K})$, sodium $(\mathrm{Ca})$ and magnesium $(\mathrm{Mg})$ was also increased compared to the non AM Gigaspora gigantia soybean plants in low Phosphorus. At the same time Gigaspora gigantia colonized maize plant was decreased $(\mathrm{K})$ and $\mathrm{Ca}$ but increased $\mathrm{Mg}$ acquisition. Aleminum (Al) acquisition toxicity was lower in AM switch grass grown in acidic soil compared to non AM plants (Clark, 1997).

Mycorrhizosphere: Mycorrhizosphere refers to the zone of soil influence by mycorrhizalassociation. The first reported 
about the role of the mycorrhizosphere in biocontrol of pathogens was by Meyer and Linderman (1986). They found that extracts of rhizosphere soil from mycorrhizal plants reduced sporangia formation of Phytophthora cinnamomi in comparison with extracts of rhizosphere soil from non-mycorrhizal plants. These authors postulated that either the sporulation-inducing microorganisms were missing or that the number of sporulationinhibiting microorganisms increased. The changes in root exudates affect the microbial communities around the roots leading to the formation of mycorrhizosphere. In mycorrhizosphere the appearance of mycorrhizae exert a strong influence on the microflora in the rhizosphere. The mycorrhizosphere microbiota differs qualitatively as well as quantitatively from the non rhizosphere mycorrhizal plants.

Summary and conclusion are as follows:

The real essence of mycorrhizal association is that it benefits the primary producers by combating diseases, supplying essential nutrients required for growth. In the light of the current scenario what seems to be essential is the identification of the mechanism and nature of interaction and the key genes from fungi as well as the plants that regulate the interaction. Despite all these benefits present day practices of agriculture may lead to the destruction of these beneficial associations. Anthropogenic activities like slash and burn cultivation, mining, waste disposal, and clear-cutting of forests are also detrimental to mycorrhizae. Ruthless use of pesticides \& fertilizers have not only degraded the environment but also risked the lives of millions of living organisms, so stress on ecofriendly substitutes like mycorrhiza should be more. Stress should be laid on the identification of more useful strains of mycorrhiza which can thrive in any environmental condition.A well-documented knowledge about mycorrhizal trade offs as well as a complete understanding of the mechanism of interaction will be essential to advance mycorrhizal technology for a better tomorrow.

\section{References}

Aguilar, C. and Barea, J.M. 1997. Applying mycorrhiza biotechnology to horticulture: Significance and potentials. Scientia Horticulturae, 68:1-24

Benjamin, R.K., 1979. Zygomycetes and their Spores. In: The whole Fungus: The Sexual Asexual Synthesis, Kendrick, B. (Ed.). National Museums of Natural Canada, Ottawa, Canada, pp: 573-622.

Bethlenfalvay, G.J. and Schuepp, H. 1994. Arbuscular Mycorrhizas and Agrosystem Stability. In: Impact of Arbuscular Mycorrhizas on Sustainable Agriculture and Natural Ecosystems, Gianinazzi, S. and Schuepp, H. (Eds.). Birkhauser Verlag, Basel, Switzerland, pp: 117-131.

Cardoso, I.M., Boddington, B.H., Janssen, O. and Oenema-Kuyper, T.W. 2006. Differential access to phosphorus pools of an oxisol by mycorrhizal and nonmycorrhizal maize. Journal. Communications in Soil Science and Plant Analysis37: 1537-1551.

Clark, R.B. and Zeto, S.K. 2000. Mineral acquisition by arbuscular mycorrhizal plants. Journal of Plant Nutrition23: 867902.

Clark, R.B., 1997. Arbuscular mycorrhizal adaptation, spore germination, root colonization and host plant growth and mineral acquisition at low $\mathrm{pH}$. Plant \& Soil192: 15-22.

Cordier, C., Gianinazzi, S. and GianinazziPearson, V. 1996. Colonisation patterns of root tissues by Phytophthora nicotianae var. parasitica related to reduced disease in mycorrhizal tomato. Plant\& Soil185: 223232.

Cordier, C., Pozo, M.J., Barea, J.M., Gianinazzi, S. and Gianinazzi-Pearson, V. 
1998. Cell defense responses associated with localized and systemic resistance to Phytophthora parasitica induced in tomato by an arbuscular mycorrhizal fungus. Molecular Plant-Microbe Interactions, 11: 1017-1028.

Dehne, H.W., 1982. Interaction between vesicular-arbuscular mycorrhizal fungi and plant pathogens. Phytopathology, 72: 1115-1119.

Dugassa, G.D., Von Allen, H. and Schonbeck, F. 1996. Effect of Arbuscular Mycorrhiza (AM) on health of Linumus itatissimum L. infected by fungal pathogen.Plant \& Soil185: 173-182.

Gianinazzi, S., Trouvelot, A., Lovato, P., Van Tuinen, D., Franken, P. and GianinazziPearson, V. 1995. Arbuscular mycorrhizal fungi in plant production of temperate agroecosystems. Critical Reviews in Biotechnology 15: 305-311.

Gilbert, L. and Johnson, D., 2017. Plant-Plant Communication Through Common Mycorrhizal Networks. In Advances in Botanical Research (Vol. 82, pp. 83-97). Academic Press.

Gosling, P., Hodge, A., Goodlass, G. and Bending, G.D. 2006. Arbuscular mycorrhizal fungi and organic farming. Agriculture, Ecosystems \& Environment 113: 17-35.

Graham, J.H. 1982. Effect of citrus root exudates on germination of chlamydospores of vesicular-arbuscular mycorrhizal fungus Glomus epigaeum. Mycologia74: 831-835.

Grandmaison, J., Olah, G.M., VanCalsteren,M.R., and Furlan, V. 1993. Characterization and localization of plant phenolics likely involved in the pathogen resistance expressed by endomycorrhizal roots. Mycorrhiza3: 155-164.

Grosch, R., Lottmann, J., Faltin, F. and Berg, G. 2005. Use of bacterial antagonists to control diseases caused by Rhizoctonia solani. Gesunde Pflanzen, 57: 199-205.

Hawkins, H.J. and George, E. 2001. Reduced N15-nitrogen transport through arbuscular mycorrhizal hyphae to Triticum aestivum
L. supplied with ammonium vs. nitrate nutrition. Annals of Botany87: 303-311.

Khaosaad, T., Garcia-Garrido, J.M., Steinkellner, S. and Vierheilig, H. 2007. Take-all disease is systemically reduced in roots of mycorrhizal barley plants. Soil Biology and Biochemistry 39: 727-734.

Li, X.L., George, E. and Marschner, H. 1991. Extension of the phosphorus depletion zone in VA-mycorrhizal white clover in a calcareous soil. Plant \& Soil 136:41-48.

Linderman, R.G., 1994. Role of VAM Fungi in Biocontrol. In: Mycorrhizae and Plant Health, Pfleger, F.L. and Linderman, R.G. (Eds.). The American Phytopathological Society, St. Paul, MN., USA., ISBN: 089054-158-2, pp: 1-27

Lu, L.H., Zou, Y.N. and Wu, Q.S., 2019. Mycorrhizas mitigate soil replant disease of peach through regulating root exudates, soil microbial population, and soil aggregate stability. Communications in Soil Science and Plant Analysis (pp.1-13).

Marschner, P., Crowley, D. and Lieberei, R. 2001. Arbuscular mycorrhizal infection changes bacterial 16s DNA community composition in the rhizosphere of maize. Mycorrhiza 11: 297-302.

Meyer, J.R. and Linderman, R.G. 1986. Selective influence on population of rhizospher or rhizoplane bacteria and actinomycetes by mycorrhizas formed by Glomus fasciculatum. Soil Biology and Biochemistry18: 191-196.

Morandi, D., 1996. Occurrence of phytoalexins and phenolic compounds in endomycorrhizal interactions and their potential role in biological control. Plant \& Soil185: 241-251

Raju, P.S., Clark, R.B., Ellis,J.R. and Maranville, J.W. 1990. Effects of species of VA-Mycorrhizal fungi on growth and mineral uptake of sorghum at different temperatures. Plant \& Soil 121: 165-170.

Ranganathswamy, M., Kadam, G.L. and Jhala, Y.K., 2019. An Insight into Mycorrhiza Involved in Building Soil and Plant Health. In: Soil Fertility Management for Sustainable Development (pp. 211-229). 
Springer, Singapore.

Remy, W., Taylor, T.N., Hass, H. and Kerp, H. 1994. Four hundred million year old vesicular arbuscular mycorrhizae. Proceedings of the National Academy of Sciences USA 91:11841-11843.

Schreiner, R.P. and Bethlenfalvy, G.J. 1995. Mycorrhizal interactions in sustainable agriculture. Critical Reviews in Biotechnology 15: 271-287.

Secilia, J. and Bagyaraj, D.J. 1987. Bacteria and actinomycetes associated with pot cultures of vesicular-arbuscular mycorrhizas. The Canadian Journal of Microbiology 33: 1069-1073.

Sharma, M.P., Gaur, A. and Mukerji, K.G. 2007. Arbuscular Mycorrhiza Mediated Plant Pathogen Interactions and the Mechanisms Involved. In: Biological Control of Plant Diseases, Sharma, M.P., Gaur, A. and Mukerji, K.G. (Eds.). Haworth Press, Binghamton, USA., pp: 47-63.

Simon, L., Bousquet, J., Levesque, R.C. and Lalonde, M. 1993. Origin and diversification of endomycorrhizal fungi and coincidence with vascular land plants.Nature363: 67-69.

Smith, S.E. and Read, D.J. 1997. Mycorrhizal Symbiosis. 2nd Edn., Academic Press, London, UK., ISBN-13: 978-0-12-6528404, Pages: 605

Smith, S.E. and Read, D.J. 2008. Mycorrhizal symbiosis. 3rd Edn., Academic Press, London, UK., Pages: 800.

Sreenivasa, M.N. and Bagyaraj, D.J. 1989. Use of pesticides for mass production of vesicular-arbuscular mycorrhizal inoculum. Plant and Soil 119: 127-132.

Strack, D., Fester, T., Hause, B., Schliemann, W. and Walter, M.H. 2003. Arbuscular mycorrhiza: Biological, chemical and molecular aspects. Journal of Chemical Ecology 9: 1955-1979.

Sturz, A.V., Carter, M.R. and Johnston, H.W. 1997. A review of plant disease, pathogen interactions and microbial antagonism under conservation tillage in temperate humid agriculture.Soil and Tillage Research41: 169-189.

Tahat, M.M., Kamaruzaman, S.,Radziah, O.,Kadir,J. and Masdek, H.N. 2008. Response of (Lycopersicum esculentum Mill.) to different arbuscular mycorrhizal fungi species. Asian Journal of Plant Sciences 7: 479-484.

Wani, A.H. and Mir, R.A., 2009. Biological control of Fusarium oxysporum f. sp. lycopercici on tomato with fungal antagonists. Journal of Biological Control 23(2): 169-173.

Ziedan, E.S., Elewa, I., Mostafa, M. and Sahab, A., 2011.Application of mycorrhizae for controlling root diseases of sesame. Journal of Plant Protection Research 51(4): 355-361.

\section{How to cite this article:}

Mashoq Ahmad, Baby Summuna, Sachin Gupta and Sheikh, P.A. 2020. Mycorrhizal Association: An Important Tool for the Management of Root Diseases. Int.J.Curr.Microbiol.App.Sci. 9(09): 1958-1966. doi: https://doi.org/10.20546/ijcmas.2020.909.246 